\title{
28 Research Soure \\ Experimental Study of Ultrasonic Vibration Effects on Punch Radial in Sheet Hydroforming Process
}

\section{Reza Ghasemi}

Babol Noshirvani University of Technology

Majid Elyasi ( $\square$ elyasi@nit.ac.ir)

Babol Noshirvani University of Technology

Hamid Baseri

Babol Noshirvani University of Technology

Mohammad Javad Mirnia

Babol Noshirvani University of Technology

\section{Research Article}

Keywords: ultrasonic vibration, hydroforming, deep drawing, forming.

Posted Date: December 6th, 2021

DOI: https://doi.org/10.21203/rs.3.rs-1121252/v1

License: (c) (1) This work is licensed under a Creative Commons Attribution 4.0 International License. Read Full License 


\section{Abstract}

Nowadays, one of the metal forming processes that are widely used in industries is sheet hydroforming. Because of high complexity and sensitivity, this process needs precise calculations in the die and method to control metal flow correctly and prevent defects. Therefore recently, new processes were combined to this process to increase precision and effectiveness. For example, ultrasonic vibration assistance forming. Using hydroforming and ultrasonic vibration as new methods were studied in several research types separately, and each of them redounded to different analyses and improvements in the process. Even synchronic use of these two methods was studied in some metal forming processes such as tube hydroforming, but it has not been studied in sheet hydroforming. Therefore the aim of this research is the experimental study of St14 sheet hydroforming ultrasonic vibration assistance. For this purpose, ultrasonic vibration (with $20 \mathrm{KHz}$ frequency and $4 \mu \mathrm{m}$ amplitude) was applied to a hydromechanical deep drawing die into punch radial in the hydroforming process. Then process parameters consisting of LDR, maximum height, forming force, safe working zone, and thickness distribution were determined and compared in four case states conventional deep drawing(CDD), hydroforming deep drawing(HDD), ultrasonic vibration assistance deep drawing(UDD) and ultrasonic vibration assistance hydroforming deep drawing(UHDD). Results indicated that applying ultrasonic vibration into the sheet hydroforming process increases LDR and the maximum height of the cup, decreases forming force and develops a safe working zone. Also was very effective in thickness distribution and decrease of sheet thinning in critical sections.

\section{Introduction}

Hydroforming is one the most commonly used sheet metal forming methods due to its numerous advantages. These include high surface quality, high dimensional accuracy resulting from spring return, reducing the number of parts production stages, and forming complex shapes. However, hydroforming requires high computational accuracy in die and process design in terms of complexity and high sensitivity to properly control metal flow and prevent defects. The sheet hydroforming process is one of the deep drawing methods. In order to overcome the limitations of the deep drawing process, in addition to applying pressing force, fluid pressure is also used for forming operations $[1,2]$. The fluid can replace the punch or matrix in the conventional deep drawing process in the sheet hydroforming process. This process is divided into two general categories, matrix-fluid and punch-fluid [1].

Due to the disadvantages of the sheet hydroforming process, such as increasing the forming force and low process speed, relatively new processes have been used in combination with it; one of these methods is forming with the assistance of ultrasonic vibration. Ultrasonic vibration are made of sound waves generated by the vibrational motion of matter and are transmitted by the material environment and transfer the energy from the vibration source. These waves are mechanical longitudinal vibrations (with a frequency range of 20 to $100 \mathrm{kHz}$ ) and can pass through materials and transfer energy. Therefore, it can also be used in metal forming processes [3]. 
The application of ultrasonic vibration to the plasticity behavior of metals began in the 1950s. The first investigation on the effect of ultrasonic vibration on the plastic deformation behavior of metals was conducted by Blaha and Langenecker in 1955 [4]. They tested the strain of single-crystal metal specimens immersed in Tetrachloromethane under the influence of ultrasonic vibration with a wide frequency range (up to $800 \mathrm{kHz}$ ). Ultrasonic vibration increased the strain until the moment of fracture and also increased the ultimate tensile strength. They concluded that ultrasonic energy is more effective than thermal energy in reducing tensile stress due to the more excellent absorption of ultrasonic in the dislocations, which increases the plastic flow of the material. Later, the phenomenon of reducing flow stress by applying ultrasonic vibration observed in different metals was known as Blaha or volume effect.

Nevill and Brotzen [5] suggested that the reduction in flow stress could be easily attributed to the superposition mechanism of stress because although the mean applied stress was reduced, the maximum stress was equal to the yield stress. In 1966, Langenecker investigated the effect of ultrasonic vibrations on the mechanical properties of metals such as zinc and aluminum and showed that in the tensile test, the results could not be explained by acoustic stress alone. He subsequently explained the various possible mechanisms and suggested that the reduction of the yield stress is directly proportional to the ultrasonic energy applied to the sample. The superposition mechanism prevails when the high thermal energy above the sample causes it to soften [6].

In addition, ultrasonic effects on friction properties were reported as surface effects. For example, Pohlman, E. Lehfeldt [7] also studied the effects of external friction. By applying vibrations in three directions perpendicular to the slip surface, they found that the friction was reduced in all cases. It is attributed to unwanted ultrasonic shearing due to adhesion of the surface due to local pressure.

In general, the mechanism of effectiveness of ultrasonic vibration in metal forming processes is divided into two categories: surface effects (macroscopic) and volume effects (microscopic) [8-11]. the surface effects of ultrasonic vibration in the metal forming processes are the reduction of sliding friction at the contact surfaces of the die and the workpiece (ultrasonic lubrication) $[12,13]$ and the reduction of spring back and dimensional and geometric stability of the workpiece [14]. The volume effects of ultrasonic vibration in metal forming processes also include changes in brittleness and plasticity (acoustic softening or hardening property) or the same effect of Blaha and Langenecker [4], significant reduction of forming force [10], increasing formability [12] and changes in microstructure [15].

Due to these promising results, various researches have been done on ultrasonic vibration in various metal forming processes. Almost all of them with ultrasonic vibration, a significant improvement in the forming process were reported both in reducing the forming force and increasing the apparent formability. It has been reported, and various theories have been proposed for these observations.

For example, in the deep drawing process, which is close to the subject of research in this article, Kristoffy [10] investigated the effect of ultrasonic vibration on the deep drawing process by applying vibration to punch(axial) and matrix(radial) separately and combinatory on AISI4130 and AL1010. He concluded that 
applying ultrasonic vibrations has generally reduced the forming force (about $20 \%$ ). In addition, by an increase of vibrations amplitude, there will be more decrease informing forces.

Then Jima et al. [16] also studied different methods of applying ultrasonic vibration in the die of deep drawing to improve the process and showed that by applying vibration with frequency 20 and $28 \mathrm{kHz}$ frequency, the limiting drawing ratio (LDR) from 2.68 to 3.01 , from 2.58 to 2.94 and from 2.38 to 2.77 for deep-drawing steel sheet (SPCE), cold-rolled steel sheet (SPCC) and stainless steel (SUS304), incased. However, they observed that the application of axial vibration in different parts of the deep drawing die leads to higher LDRs than radial vibration.

For the first time, Huang et al. [17] investigated the micro-scale deep drawing process with ultrasonic vibration on 304 stainless steel foils in different thicknesses to determine the effect of ultrasonic vibration on the formability and LDR of the specimens. They showed that applying ultrasonic vibration to the matrix increases the LDR for different thicknesses, and the amplitude of oscillation affects the LDR and the quality of the cup.

In a similar case, Shaykholeslami et al. [18] numerically studied and simulated the finite element method of a cylindrical deep drawing process with a rubber matrix in the presence of ultrasonic vibration and analyzed the effect of amplitude and frequency of ultrasonic vibration on this process. They applied vibration axially to the punch and performed simulations at three frequencies and three amplitudes. As a result of this research, it was found that the forming force is significantly reduced, and also, with increasing the amplitude and frequency, the forming depth increases, and the process stability improves.

Kakinoki et al. [19] also introduced a method for detecting the amount of Wrinkling in the sheet forming process using ultrasonic vibrations. For this purpose, by applying ultrasonic vibration(on the $\mathrm{MHz}$ frequency scale) axially to the point of interface between the die and workpiece in a deep drawing die and measuring its relative reflection intensity, they were able to measure the number of wrinkles during the process and determine parameters affecting it. They concluded that as the wrinkle height increases, the relative reflection intensity decreases, and as the wrinkle wavelength increases, the difference between the maximum and minimum relative reflection intensity increases.

Regarding the subject of the forthcoming research on the application of ultrasonic vibration in hydroforming, Eftekhari Shahri et al. [14] investigated the improvement of formability in the tube hydroforming process by applying ultrasonic vibration. This process was performed by simulation and experimentally to convert copper tube transversely to square profile. The results showed a significant improvement in the formability of the tube so that while the wall thickness became uniform, the forming rate increased, and the spring back decreased. In this case, Zarei et al. [20] conducted a study on hydroforming of copper tubes using ultrasonic vibration, in which they simulated the bulging process using the finite element method. This simulation introduced ultrasonic vibration into the tube longitudinally and loaded them with the specified pressure path. This study concluded that the amount of forming force depends on the amplitude of the applied vibration and can be reduced by up to $20 \%$. Also, the application of ultrasonic vibration affects increasing the diameter of the bulge. 
Given the above, it can be seen that the effects of ultrasonic vibration on the sheet hydroforming process and the study of the behavior of metal sheet forming in the presence of oil pressure, under the influence of this vibration in none of its states have been studied. Therefore, the purpose of this study is to predict the double efficiency of the hydroforming process with the presence of ultrasonic vibration, using ultrasonic vibration in sheet hydroforming die (radially on the punch), and to investigate its effects so that the benefits of both methods can be used. It increased formability as much as possible.

For this purpose, the effect of ultrasonic vibration on the sheet hydroforming process has been investigated experimentally to determine the effects of applying ultrasonic vibration on the parameters of the sheet hydroforming process compared to the conventional deep drawing. Ordinary and straightforward sheet hydroforming will change. it is necessary to first explain how to apply ultrasonic vibration in sheet hydroforming to the punch in the radial state and then determine the quantitative and qualitative effects of applying ultrasonic vibrations in sheet hydroforming.

\section{Finite Element Simulation}

In this research was used finite element simulation by ABAQUS software for punch modal analysis to determining optimum installation position, dimensional and geometric properties until resonance frequency and maximum effect of ultrasonic vibration is generated on punch. Considering punch diameter and head radius are constant, for best results modal analysis was done for different length of tool steel punch. Ultrasonic vibration frequency that applying to punch is $20 \mathrm{KHz}$ lateral then lateral resonance frequency was determined around $20 \mathrm{KHz}$. As it is shown in Fig. 1 in length of $127 \mathrm{~mm}$ nearest lateral resonance frequency was resulted. In continuation punch was made for experimental tests according to this results.

\section{Process Properties}

\subsection{Sheet properties}

Used sheet in this research is St14 by nominal thickness $0.5 \mathrm{~mm}$. Selection of this material was operational use in industry and adequate results in similar researches. The material properties St14 are showed in Table 1. 
Table 1

Material properties of St14 [21]

\begin{tabular}{|ll|}
\hline Properties & Value \\
\hline Densiy, $\rho\left(\mathrm{Kg} / \mathrm{m}^{3}\right)$ & 7850 \\
\hline Young's modulus, $\mathrm{E}(\mathrm{GPa})$ & 210 \\
\hline Initial yield stress, $\sigma_{\mathrm{y} 0}(\mathrm{MPa})$ & 159 \\
\hline Poisson's ratio & 0.3 \\
\hline Ultimate stress, $\sigma_{\mathrm{u}}(\mathrm{MPa})$ & 283 \\
\hline Hardening coefficient, $\mathrm{K}(\mathrm{MPa})$ & 630 \\
\hline Hardening powe, $\mathrm{n}$ & 0.36 \\
\hline
\end{tabular}

\subsection{Pressure path}

Hydraulic pressure path that applied to hydroforming die chamber is shown in Fig. 2. According this, primary pressure $3 \mathrm{MPa}$ is primary bulge pressure that applied by a hydraulic hand pump to bottom surface of sheet before punch movement. After vertical punch movement into die and sheet drawing, die chamber pressure increase incrementally until reach to adjusted value $10 \mathrm{MPa}$ on pressure control valve.

\subsection{Loading properties}

As it is shown in Fig. 3, when ultrasonic vibration is applying to punch radial in sheet hydroforming process, loading along punch axis ( $Z$ axis) is constant velocity and loading along lateral axis ( $X$ axis) is oscillating that follow Eq. (1 to 4 ). In this compound loading, physical properties was calculated according generated vibration by ultrasonic power supply and showed in Table 2 .

Table 2

\begin{tabular}{|ll|}
\hline Oscilation loading properties \\
\hline Properties & Value \\
\hline Frequency $(\mathrm{Hz})$ & 20000 \\
\hline Amplitude $(\mu \mathrm{m})$ & 4 \\
\hline Wave length $(\mathrm{mm})$ & 259 \\
\hline Period $\left(10^{\wedge}-5 \mathrm{~s}\right)$ & 5 \\
\hline$\omega(\mathrm{rad} / \mathrm{s})$ & $40000 \pi$ \\
$\mathrm{v}(\mathrm{mm} / \mathrm{s})$ & 5 \\
\hline
\end{tabular}




$$
\begin{aligned}
& \mathrm{U}_{1}(\mathrm{t})=-\mathrm{vt} \\
& \mathrm{U}_{2}(\mathrm{t})=\mathrm{aSin}(\omega \mathrm{t})
\end{aligned}
$$

According to values in Table 2:

$$
\begin{aligned}
& \mathrm{U}_{1}(\mathrm{t})=-5 \mathrm{t}[\mathrm{mm}] \text { or }-5000 \mathrm{t}[\mu \mathrm{m}] \\
& \mathrm{U}_{2}(\mathrm{t})=4 \operatorname{Sin}(40000 \pi \mathrm{t})[\mu \mathrm{m}]
\end{aligned}
$$

Finally, there is a compound oscillating loading in die that combined from a linear and oscillating movement in two different planes. Also in hydroforming tests there is a hydrostatic pressure in die chamber according to pressure path.

\section{Experimental Study}

\subsection{Laboratory equipment}

\subsubsection{Die properties}

Used hydroforming die in experimental tests as shown in Fig. 4 is a hydromechanical die- fluid die. Schematic of this sheet hydroforming die with hydraulic circuit is showed in Fig. 5 and its dimensional properties is according to Table 3 . All tests are done in ambient temperature and forming process is cold working. To produce hydraulic pressure in die chamber was used a hydraulic hand pump and hydraulic oil HLP68 in primary pressure range 0 to $3 \mathrm{MPa}$ with pressure control valve for achievement final pressure. As it is shown in Fig. 5 in this die for sealing die chamber between die- blank holder and punch- blank holder was used adequate 0 -rings.

Used hydroforming process in this research is hydromechanical type and a 25ton hydraulic press with $5 \mathrm{~mm} / \mathrm{s}$ drawing velocity was used for drawing. In Fig. 6 equipment and their setup was showed completely.

This process was carried out for different LDRs with primary bulge pressure $3 \mathrm{MPa}$ (30bar) and final pressure $10 \mathrm{MPa}$ (100bar) to produce cup without fracture. Also ultrasonic vibration generated by a $750 \mathrm{~W}$ ultrasonic power supply with $20 \mathrm{KHz}$ frequency and $4 \mu \mathrm{m}$ amplitude that was entered to punch radial. 
Table 3

Sheet hydroforming die dimensions $(\mathrm{mm})$

\begin{tabular}{|ll|}
\hline Properties & Value \\
\hline$D_{p}$ & 40 \\
\hline$D_{d}$ & 42.4 \\
\hline Max. $D_{b}$ & 120 \\
\hline$R_{p}$ & 6 \\
\hline$R_{d}$ & 5 \\
\hline$e$ & 0.05 \\
\hline
\end{tabular}

\subsubsection{Apply ultrasonic vibration on punch}

As it is shown in Fig. 7 for transmission of vibration from piezoelectric transducer to punch, was used a titanium horn with minimum drop in amplitude and resonance frequency at its end (connect point with punch center). As for wave length of used vibration, this horn supported in nodal point by a nut on punch as its end point that have resonance install on center of punch.

\subsection{Experiment parameters and methods}

By equipment and arrangements according section 4.1, needed blanks was prepared and tests as shown in Fig. 8, was carried out in four case state: conventional deep drawing (CDD), hydroforming deep drawing (HDD), ultrasonic vibration assistance deep drawing (UDD) and ultrasonic vibration assistance hydroforming deep drawing (UHDD). In each state of experiment, test began by a minimum LDR and then LDR increased sequential by increase of blank diameter until fracture. After each test, process primary parameters such as LDR and forming force were measured. For certainty of test accuracy, each test repeated two or three time and average value was used. In Table 4 is shown parameters and results of four case state of experiments. 
Table 4

Parameters and results in in four steps of experiments

\begin{tabular}{|lllllll|}
\hline Process & First LDR & Second LDR & Final LDR & $\begin{array}{l}\text { Pre-Bulging } \\
\text { Pressure(MPa) }\end{array}$ & $\begin{array}{l}\text { Final } \\
\text { Pressure(MPa) }\end{array}$ & $\begin{array}{l}\text { Max. } \\
\text { Height(mm) }\end{array}$ \\
\hline CDD & 1.8 & 2 & 2 & 0 & 0 & 30 \\
\hline HDD & 2 & 2.1 & 2.15 & 3 & 10 & 36.2 \\
\hline UDD & 2 & 2.1 & 2.2 & 0 & 0 & 38.4 \\
\hline UHDD & 2 & 2.2 & 2.25 & 3 & 10 & 40.6 \\
\hline
\end{tabular}

\section{Results}

\subsection{LDR and Height}

To evaluate the effectiveness of the application of ultrasonic vibration on sheet hydroforming process, CCD parameters with maximum LDR 2 and maximum height $30 \mathrm{~mm}$ was considered as a primary criterion and other processes were compared with it. As shown in Fig. 9 in this comparison HDD had a $7.5 \%$, UDD had a $10 \%$ and UHDD had a $12.5 \%$ increase.

Along LDR increase, as shown in Fig. 10 maximum height of samples obtained in different processes compared with CCD, HDD had a $21 \%$, UDD had a $28 \%$ and UHDD had a $35 \%$ increase.

As can be seen from the results, the combined effect of the hydroforming and application of ultrasonic vibration in improvement of LDR and maximum height of samples is not cumulative and two process effects are merged together. Based on the experimental results, a relation can be established according to Eq. (5) between different states.

$\mathrm{UHDD}=\mathrm{UDD}+(\mathrm{UDD}-\mathrm{HDD})$

\subsection{Forming force}

To compare of forming force in four step of experiments, according to Fig. 11 the forming force diagram of each process relative to punch displacement is obtained. In this comparison, it can be seen that maximum amount of forming force is for HDD and minimum amount of forming force is for UDD with a difference about $20 \%$. But the effect of applying ultrasonic vibration in both CDD and HDD was equal and had $8 \%$ decrease. In CDD due to more friction, maximum forming force was occurred in displacement $21 \mathrm{~mm}$ but in other processes, it was occurred earlier in displacement $20 \mathrm{~mm}$, also in primary steps until the maximum forming force is reached, more force is obtained than in other. 
In HDD and UHDD due to presence of primary bulge pressure in early stages of hydroforming, at first there is an initial force, then fluctuations occur due to bulge dipping and pressure distribution at the top of the sheet to punch and blank holder sealings.

\subsection{Working zone}

As shown in Fig. 12 to determine the safe working zone in sheet hydroforming process assisted by ultrasonic vibration, according to tests performed, chamber final pressure(with two value 0 and $10 \mathrm{MPa}$ ) diagram was obtained experimental relative to different LDRs until fracture in two situations with and without ultrasonic vibration. According this, by increasing LDR in both cases of pressure) 0 and 10MPa), applying ultrasonic vibration was caused improvement. But acceptable range with $10 \mathrm{MPa}$ is more limited than OMPa. Thus in CDD By applying ultrasonic vibration to punch radially (UDD) LDR increases $10 \%$ but in HDD By applying ultrasonic vibration to punch radially (UHDD) LDR increases only $5 \%$. Therefor the combined effect of the hydroforming and application of ultrasonic vibration on sheet is incremental but is not linear and it is merged together.

\subsection{Thickness distribution}

To compare thickness distribution in four steps of experiments, from each test samples (with $0.5 \mathrm{~mm}$ initial thickness and LDR2) were cutted(by wire cut) symmetrically according to Fig. 12 and thickness was measured in different areas of cross section. As shown in Fig. 12, in all samples maximum thickness decrease is in area $B$ (the lower part of punch radius). This could be due to bending effects created in this area [22]. Also reduce the initial thickness of sheet in HDD and UHDD until $0.48 \mathrm{~mm}$ is due to thickness strain caused by primary bulge in cup bottom. Maximum thickness reduction for samples respectively is due to CDD with $20 \%$ (minimum thickness $0.40 \mathrm{~mm}$ ), HDD with $16 \%$ (minimum thickness $0.42 \mathrm{~mm}$ ), UDD with $8 \%$ ( minimum thickness $0.46 \mathrm{~mm}$ ) and UHDD with $4 \%$ ( minimum thickness $0.48 \mathrm{~mm}$ ). Also according to relative Eq. (6) maximum thickness fluctuations for samples respectively is due to CDD with $30 \%$, HDD with $26 \%$, UDD with $18 \%$ and UHDD with $12 \%$.

Deviation $=(\max . t-\operatorname{mint}) /$ initial $\mathrm{t}$

\section{t: thickness}

According to obtained results, the positive effect of ultrasonic vibration in both conventional and hydroforming deep drawing is quite obvious and same (in both cases there was a $12 \%$ improvement of maximum thickness reduction) But more important point is effect of ultrasonic vibration on thickness fluctuations so that by applying ultrasonic vibration to CDD about $12 \%$ and HDD about $14 \%$ in thickness fluctuations is improved. This means, however, effect of Applying ultrasonic vibration to conventional and hydroforming deep drawing have been uniformed and merged but its effect on thickness fluctuations is incremental so that by combining sheet hydroforming and applying ultrasonic vibration, significant uniformity is observed in thickness of samples.

\section{Conclusion}


In this research Ultrasonic Vibration applying Effects on Sheet Hydroforming Process was examined experimentally by applying Ultrasonic Vibration on punch radial in a hydromechanical deep drawing die and compared in four steps of experiments CDD, HDD, UDD and UHDD. Results show that:

1. Maximum LDR obtained compared to CDD, in HDD had a $7.5 \%$, in UDD had a $10 \%$ and in UHDD had a $12.5 \%$ increase.

2. Maximum height obtained in samples compared to CDD, in HDD had a $21 \%$, in UDD had a $28 \%$ and in UHDD had a $35 \%$ increase.

3. Maximum value of maximum forming force is due to HDD and its minimum is due to UDD with a $20 \%$ difference. Effect of applying ultrasonic vibration in both CDD and HDD is $8 \%$ decrease equally.

4. by increasing LDR in both cases of pressure ( 0 and $10 \mathrm{MPa})$, applying ultrasonic vibration was caused improvement in safe working zone. But acceptable range with $10 \mathrm{MPa}$ is more limited than $0 \mathrm{MPa}$.

Therefor the combined effect of the hydroforming and application of ultrasonic vibration on sheet is incremental but is not linear and it is merged together.

6. By applying ultrasonic vibration on sheet hydroforming, sheet thinning and thickness fluctuations were decrease significantly.

In continue, according to the experimental results, finite element simulation of applying ultrasonic vibration on sheet hydroforming is intended to comparative modeling and determining the mechanism of influence in different situations.

\section{Declarations}

\section{Author contribution}

Reza Ghasemi: investigation, experimental tests, data analysis.

Majid Elyasi: supervision, resources, conceptualization, methodology.

Hamid Baseri: resources, supervision.

Mohammad Javad Mirnia: simulation, supervision, resources.

Funding This work was supported by Babol Noshirvnai University of Technology.

Availability of data and materials Not applicable.

Code availability Not applicable.

Ethics approval Not applicable 
Consent to participate Not applicable

Consent for publication Not applicable

Competing interests The authors declare no competing interests.

\section{References}

1. S.H. Zhang, Z.R. Wang, Y. Xu, Z.T. Wang, L.X. Zhoua (2004) Recent Developments in Sheet Hydroforming Technology, Journalof Materials Processing Technology, Vol. 151, pp. 237-241.

2. S.H. Zhang, J. Danckert (1998) Development of Hydro-Mechanical Deep Drawing, Journal of Materials Processing Technology, Vol. 83, pp. 14-25.

3. D. Ensminger, L. J. Bond (1988) Ultrasonics: Fundamentals, Technology and Applications, Boca Raton: Taylor \& Francis, pp. 45-110.

4. F. Blaha, B. Langenecker (1955) Tensile Deformation of Zinc Crystal Under Ultrasonic Vibra-tion", Natuwisenschaften 42.

5. G.E. Nevill, F.R. Brotzen (1975) The effect of vibrations on the static yield strength of a low-carbon steel, Proceedings of Am. Soc. for Testing Materials, Vol. 57, pp.751-758.

6. B. Langenecker (1966) Effects of Ultrasound on Deformation Characteristics of Metals, IEEE Transactions on Sonics and Ultrasonics, Vol. 13, pp. 1-8.

7. R. Pohlman, E. Lehfeldt (1966) Influence of Ultrasonic Vibration on Metallic Friction, Ultrasonics, pp.178-185.

8. M. Lucas, A. Gachagan, A. Cardoni (2009) Research Applications andOpportunities in Power Ultrasonics", Proceedings of the Institution ofMechanical Engineers, Part C: Mechanical Engineering Science, Vol. 223, No. 12, pp. 2949-2965.

9. B. Langenecker (1961) Work-Softening of Metal Crystals by Alternating the Rate of Glide Train", Acta Metallurgica,Vol. 9, No. 10, pp. 937-940.

10. I. Kristoffy (1996) Metal Forming With Vibrated Tools, Research Associate, Physical Research Department, Cincinnati Milling Machine Company, Cincinnati, Ohio.

11. V. Fartashvand, A. Abdullah, S.A. Sadough Vanini (2016) Investigation of Ti-6Al-4V Alloy Acoustic Softening, Ultrasonic Sonochemistry, Vol. 38, pp. 744-749.

12. V.C. Kumar, I.M. Hutchings (2004) Reduction of the Sliding Friction of Metals by the Application of Longitudinal or Transverse Ultrasonic Vibration, Tribology International, Vol. 37, pp. 3833-840.

13. S. Dong, M.J. Dapino (2014) Elastic-Plastic Cube Model for Ultrasonic Friction Reduction via Poisson's Effect, Ultrasonics, Vol. 54, No. 1, pp. 343-350.

14. S. E. Eftekhari Shahri, S. Y. Ahmadi Brooghani, K. Khalili (2015) Ultrasonic tube hydroforming, a new method to improve formability, Procedia Technology, Vol. 19, 90 - 97. 
15. R.K. Dutta, R.H. Petrov, R. Delhez, M.J. MHermans, H.M. Richardson, A.J. Böttger (2015) The Effect of Tensile Deformation by in Situ Ultrasonic Treatment on the Microstructure of Low Carbon Steel, Acta Materialia, Vol. 61, pp. 1592-1602.

16. T. Jimma, Y. Kasuga, N. Iwaki, O. Miyazawa, E. Mori, K. Ito, H. Hatano (1998) An Application of Ultrasonic Vibration to the Deep Drawing Process, Journal of Materials Processing Technology, Vol.80-81, pp.406-412.

17. Y.M. Huang, Y.S. Wu, J.Y. Huang (2014) the Influence of Ultrasonic Vibration-Assisted Micro-Deep Drawing Process, The International Journal Advanced Manufacturing Technology, Vol. 71, pp.14551461.

18. M. Sheykholeslami, S. Cinquemani, S. Mazdak (2019) Numerical study of the of ultrasonic vibration in deep drawing process of circular sections with rubber die, Active and Passive Smart Structures and Integrated Systems XII, edited by Alper Erturk, Jae-Hung Han, Proc. of SPIE Vol. 1059539.

19. R. Kakinoki, Y. Segawa, Y. Marumo, Y. Imamura,

T. Nonaka, Y. Sakata (2018) Evaluation of Wrinkling States Using In-Process Ultrasonic Examination during Sheet Metal Forming, Materials Transactions, Vol. 59, No. 5, pp. 799-804.

20. M. Zarei, G. Faghani, M. Farzin, M. Mashayekhi (2017) Investigation on the Ultrasonic Tube Hydroforming in the Bulging Process Using Finite Element Method, Journal of Applied and Computational Mechanics, Vol. 3, No. 4, pp. 215-217.

21. F. H. Aboutalebi, M. Farzin, M. Poursina (2011) Numerical simulation and experimental validation of a ductile damage model for DIN 1623 St14 steel, The International Journal Advanced Manufacturing Technology, Vol. 53, pp.157-165.

22. A. Gorji, H. Alavi-Hashemi, M. Bakhshi-jooybari, S. Nourouzi, S. J. Hosseinipour (2011) "Investigation of hydrodynamic deep drawing for conicalcylindrical cups, The International Journal Advanced Manufacturing Technology, Vol. 56, No. 9, pp. 915-927.

\section{Figures}



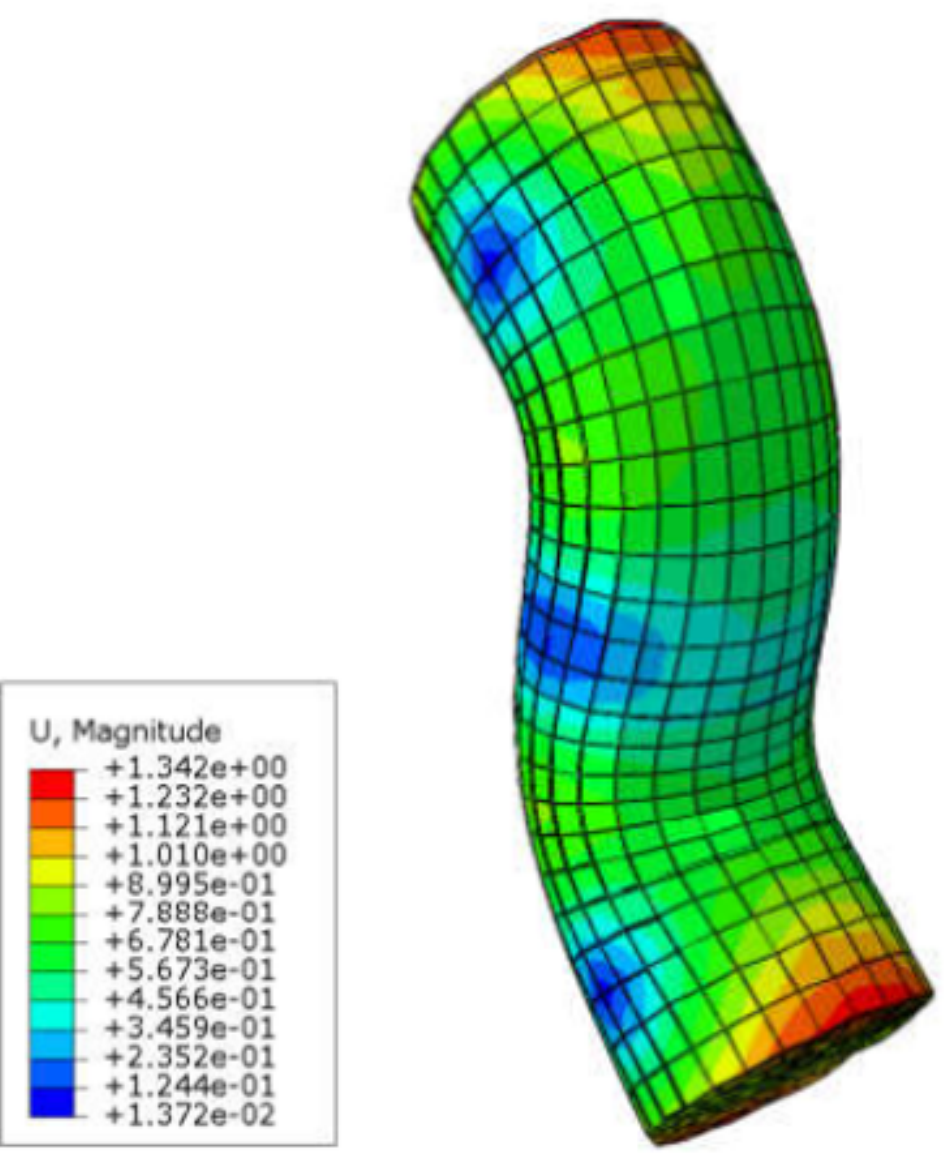

Step: Step-101

Mode $99:$ Value $=1.61605 \mathrm{E}+10$ Freq $=20232 . \quad($ cycles $/$ time $)$

Primary Var: U, Magnitude

Deformed Var: $U$ Deformation Scale Factor: $+1.270 \mathrm{e}-02$

Figure 1

Punch latheral modal Analysis

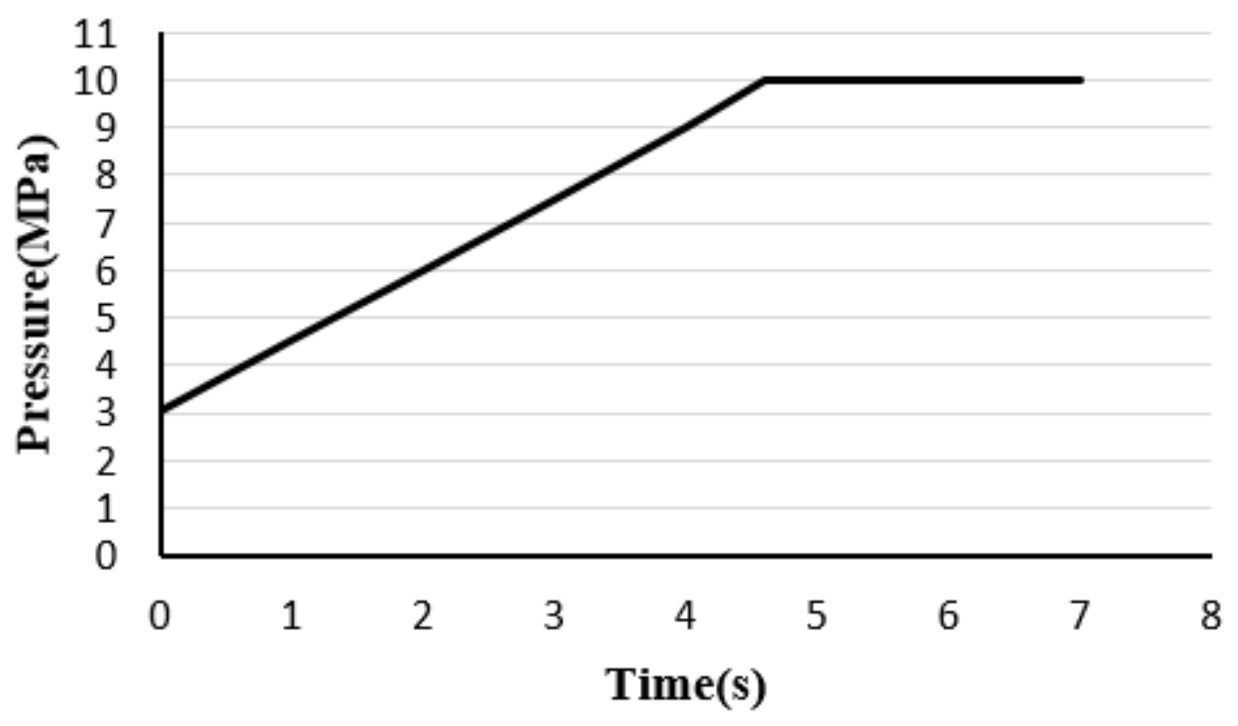


Figure 2

Pressure path

(a)
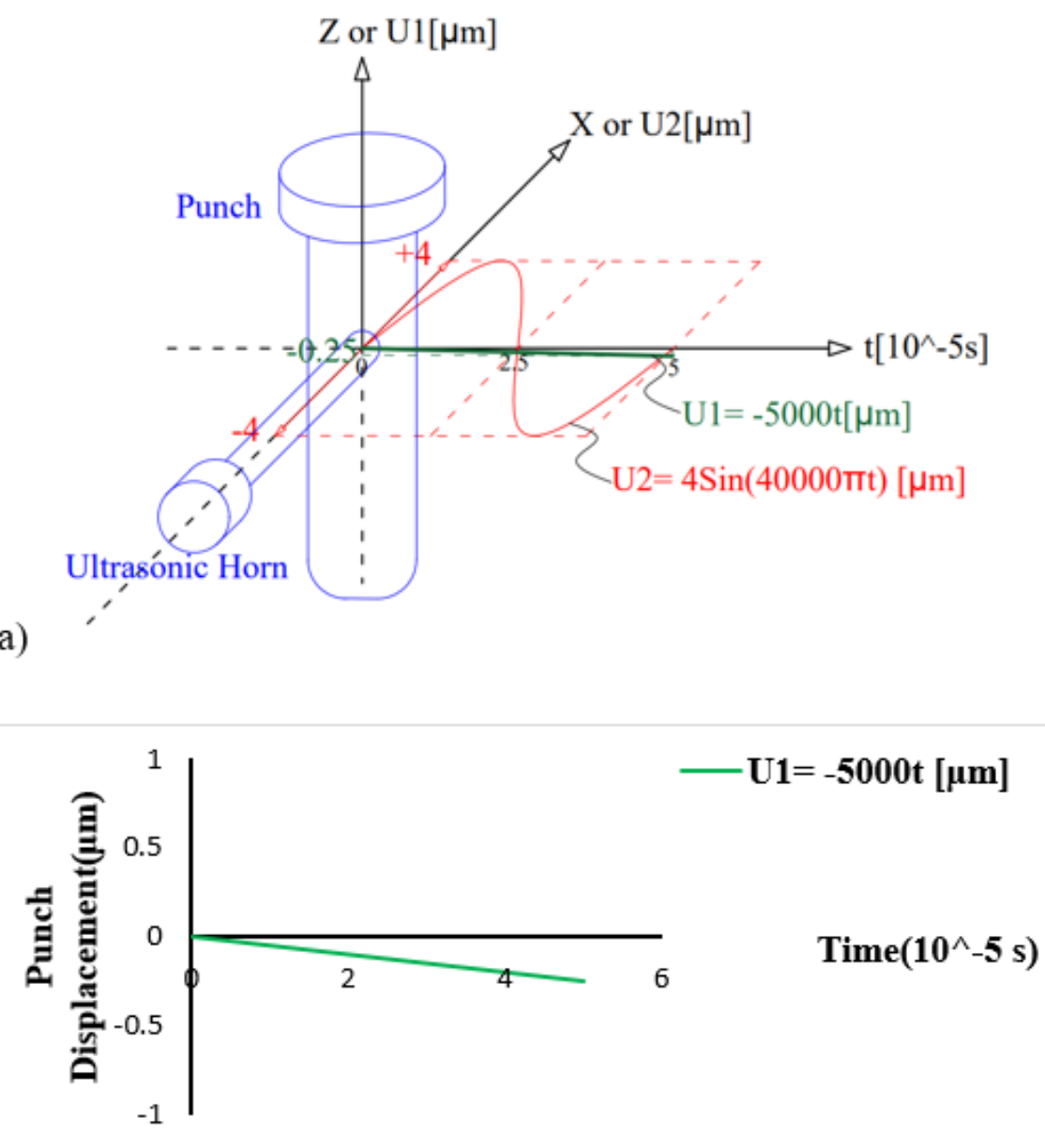

(b)

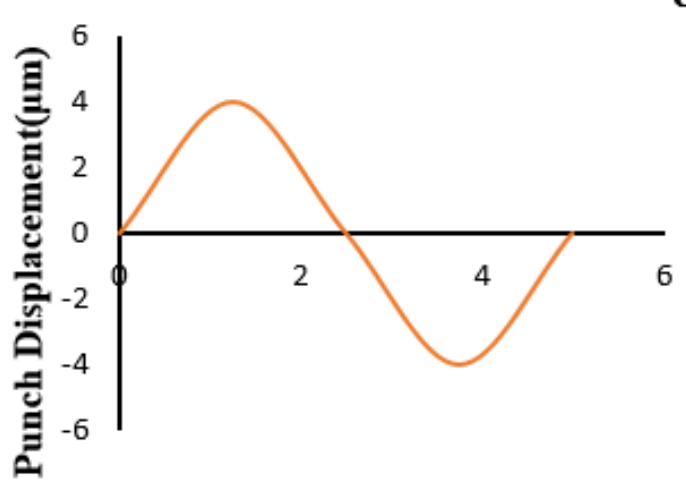

\section{$\mathrm{U} 2=4 \sin (40000 \pi \mathrm{t})[\mu \mathrm{m}]$}

Time(10^-5 s)

(c)

\section{Figure 3}

Displacement-time diagram of punch movement: a) compound movement, b) vertical movement, c) lateral oscillation movement 


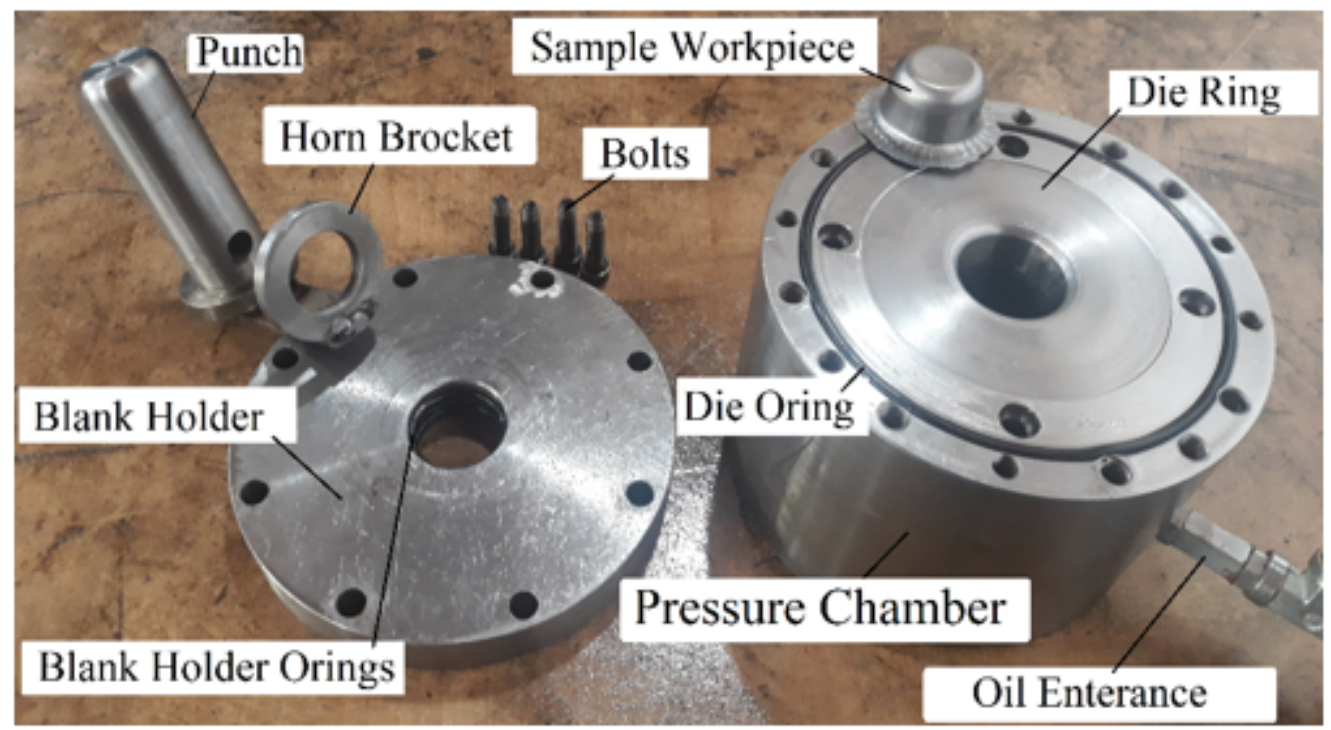

Figure 4

sheet hydroforming die details

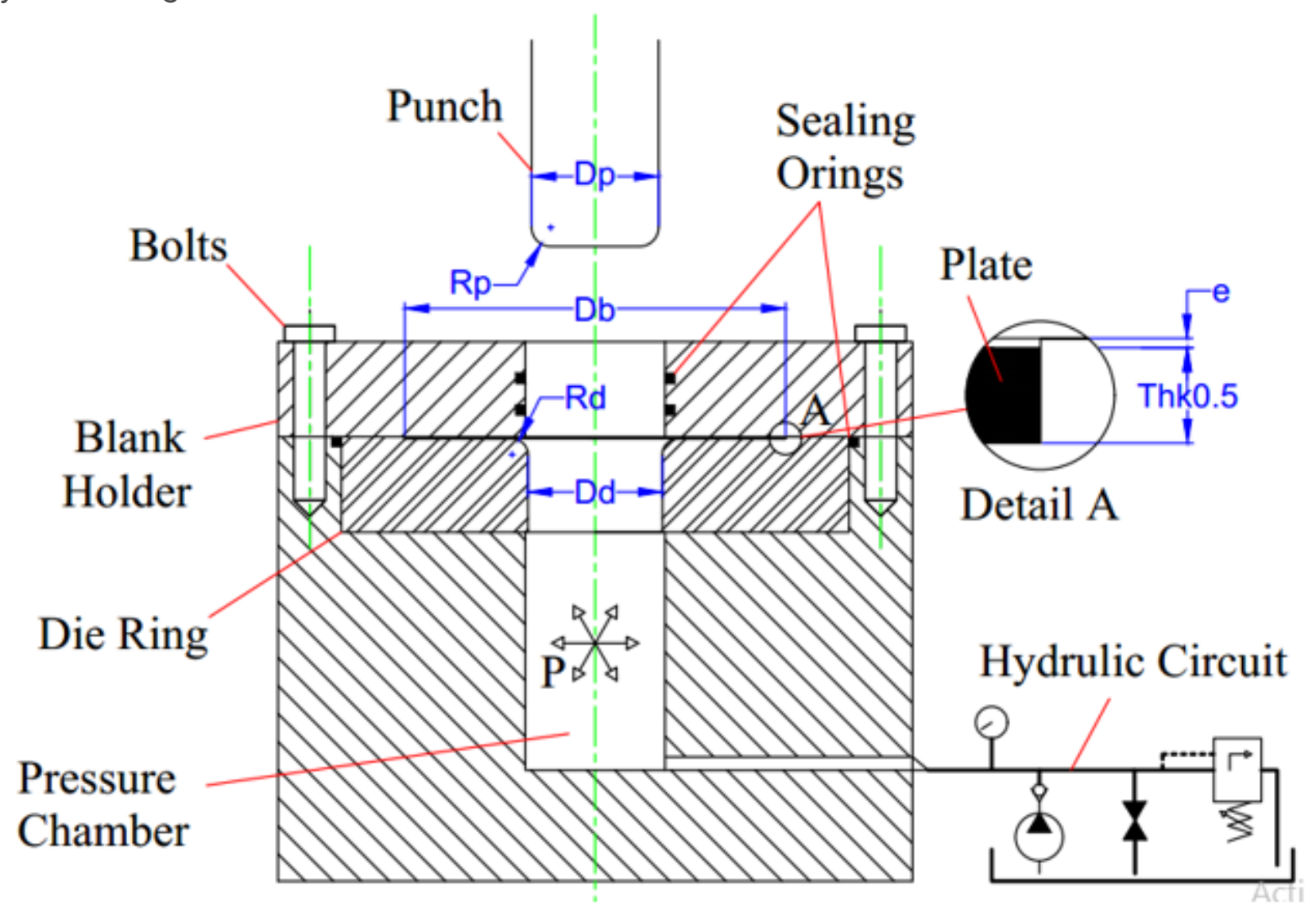

Figure 5

Schematic of sheet hydroforming die with hydraulic circuit 


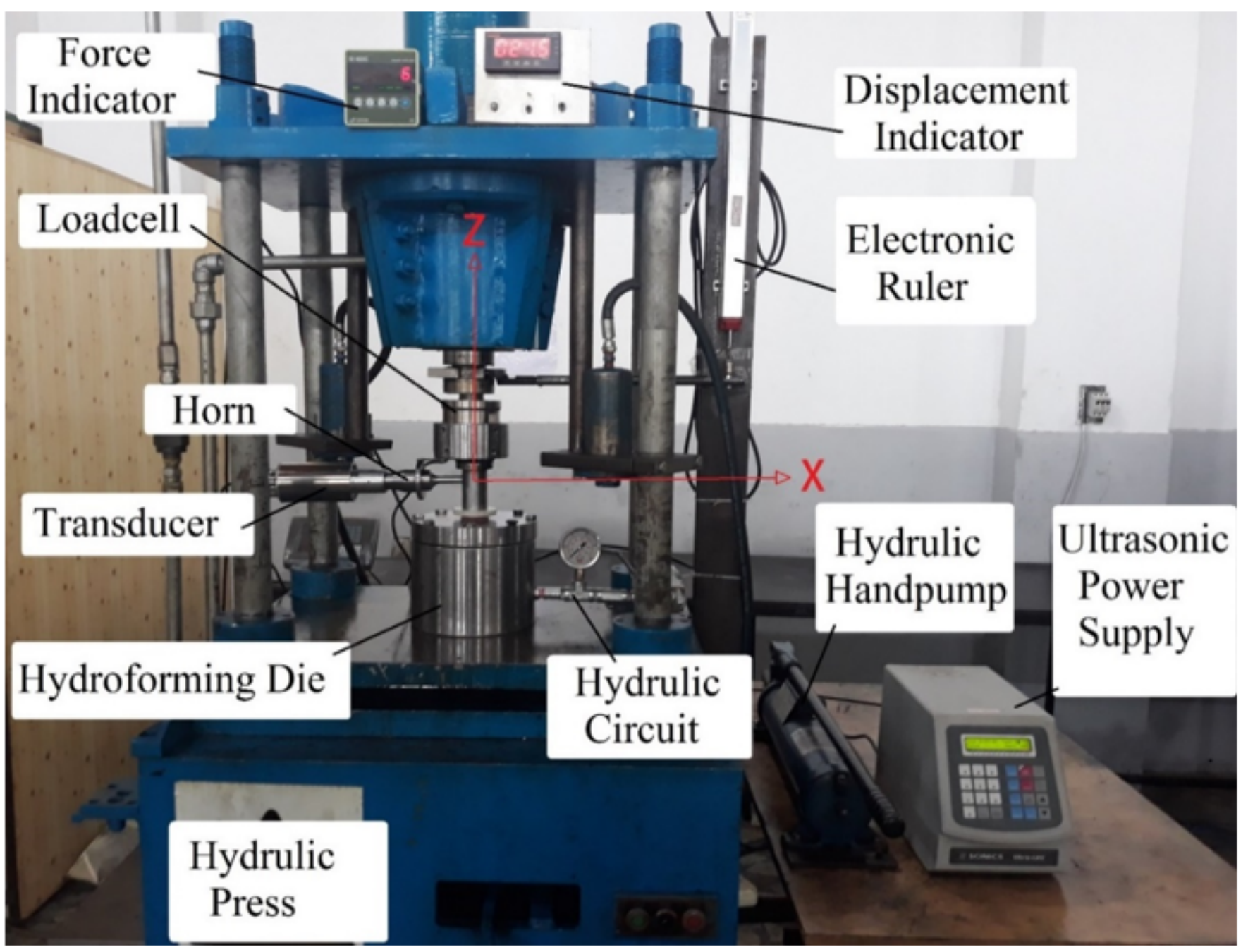

Figure 6

Equipment set up
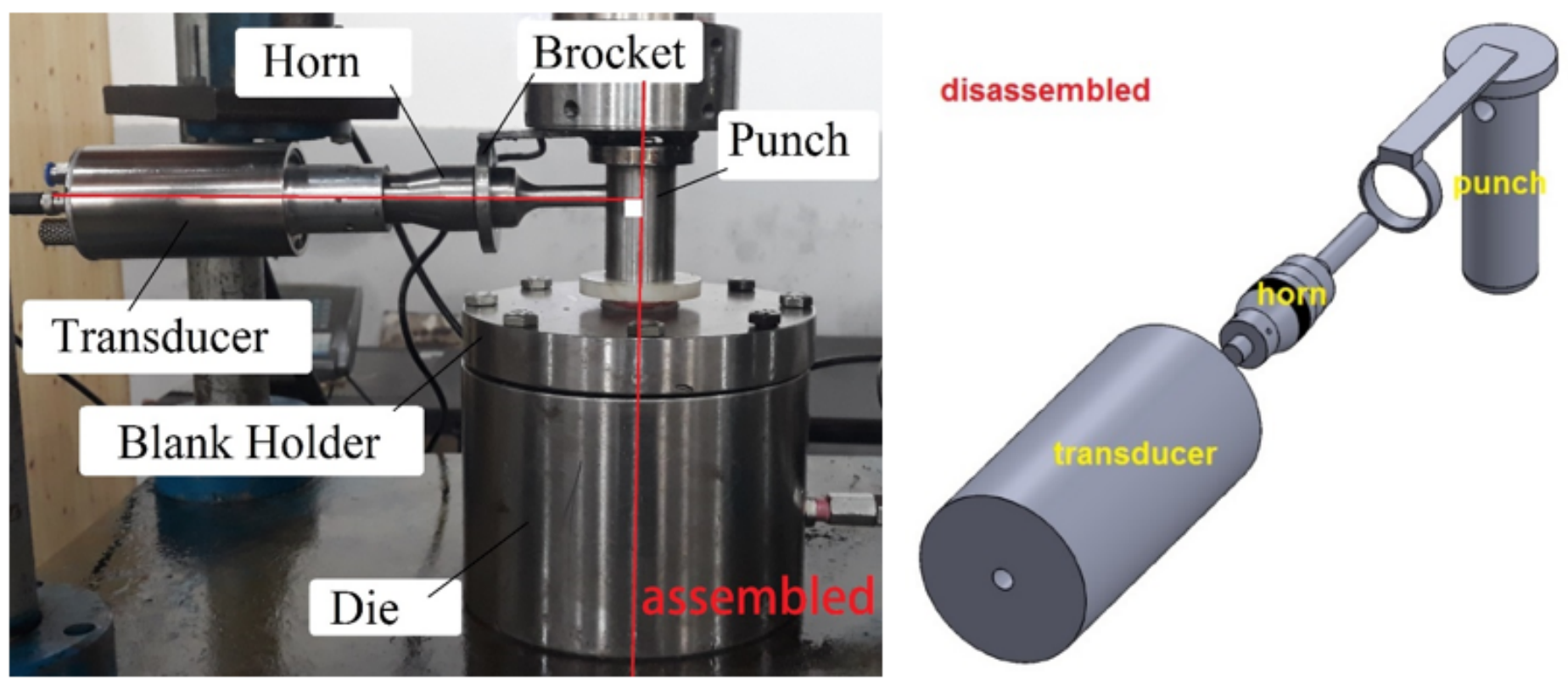
Figure 7

Schematic of applying ultrasonic vibration on punch radial

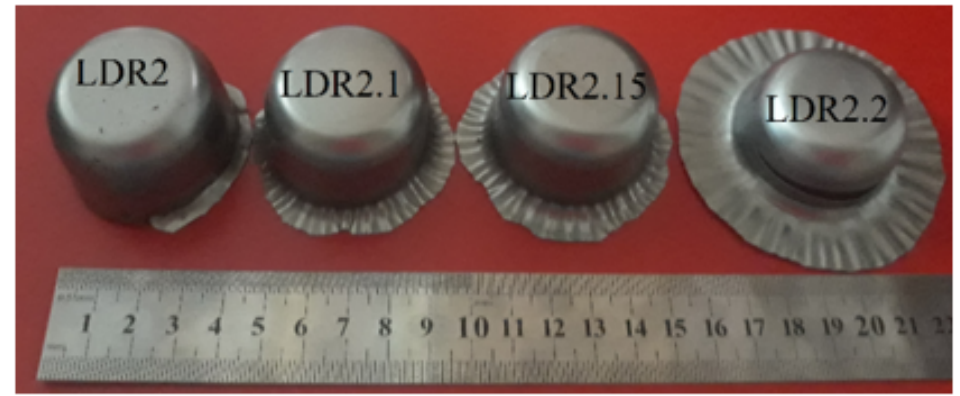

b. HDD

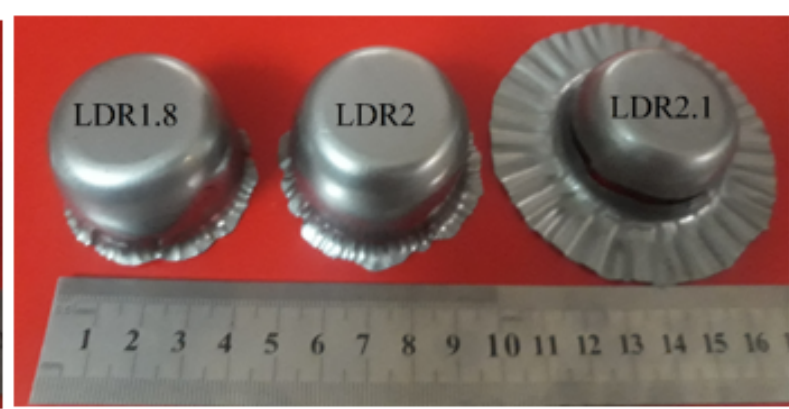

a. $\mathrm{CDD}$

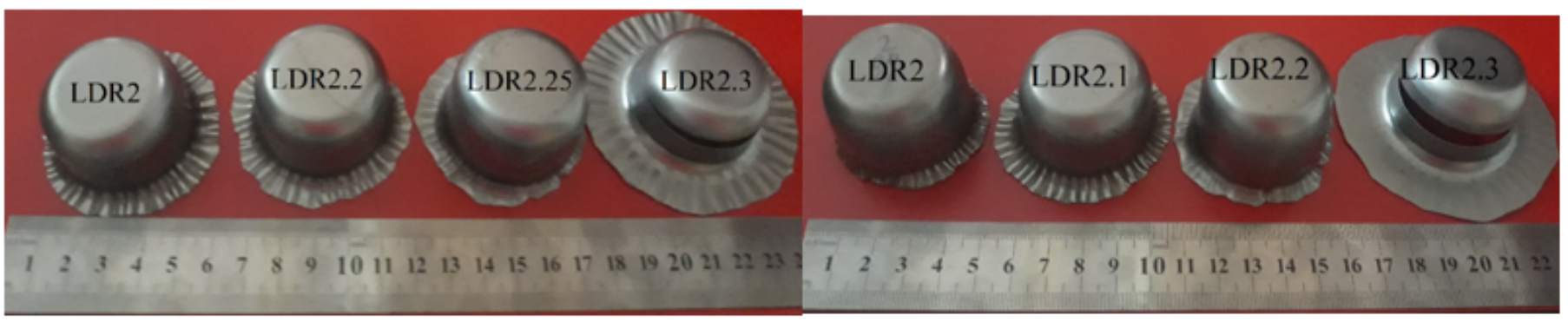

d. UHDD

c. UDD

\section{Figure 8}

Forming samples in four steps of experiments (sequential LDR to fracture)

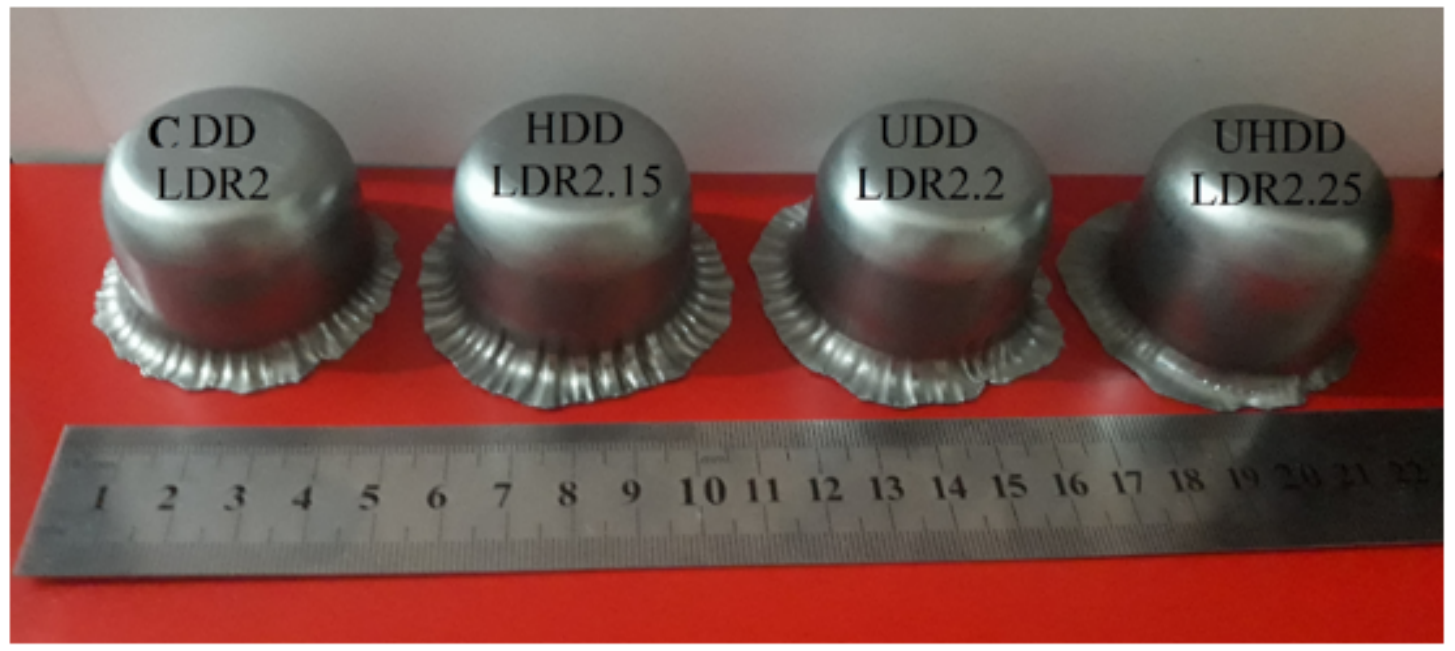

\section{Figure 9}

Compare of maximum LDR in four steps of experiments 


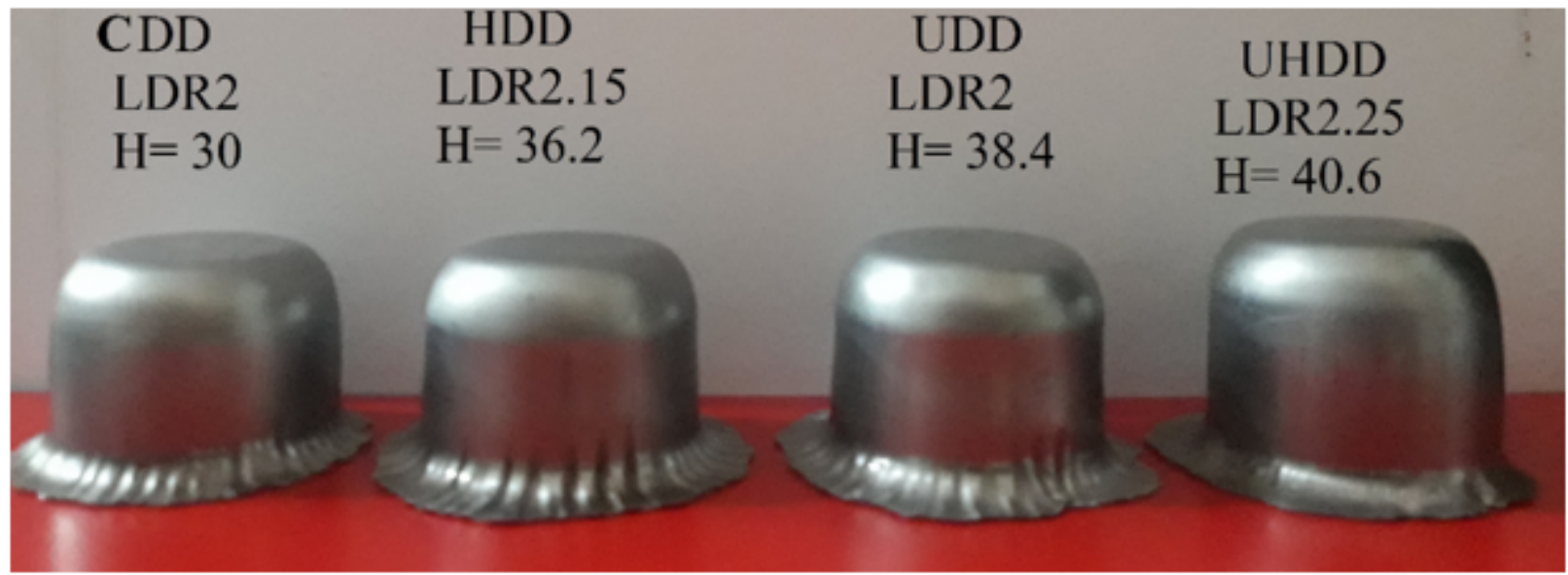

Figure 10

Compare of maximum height in four steps of experiments

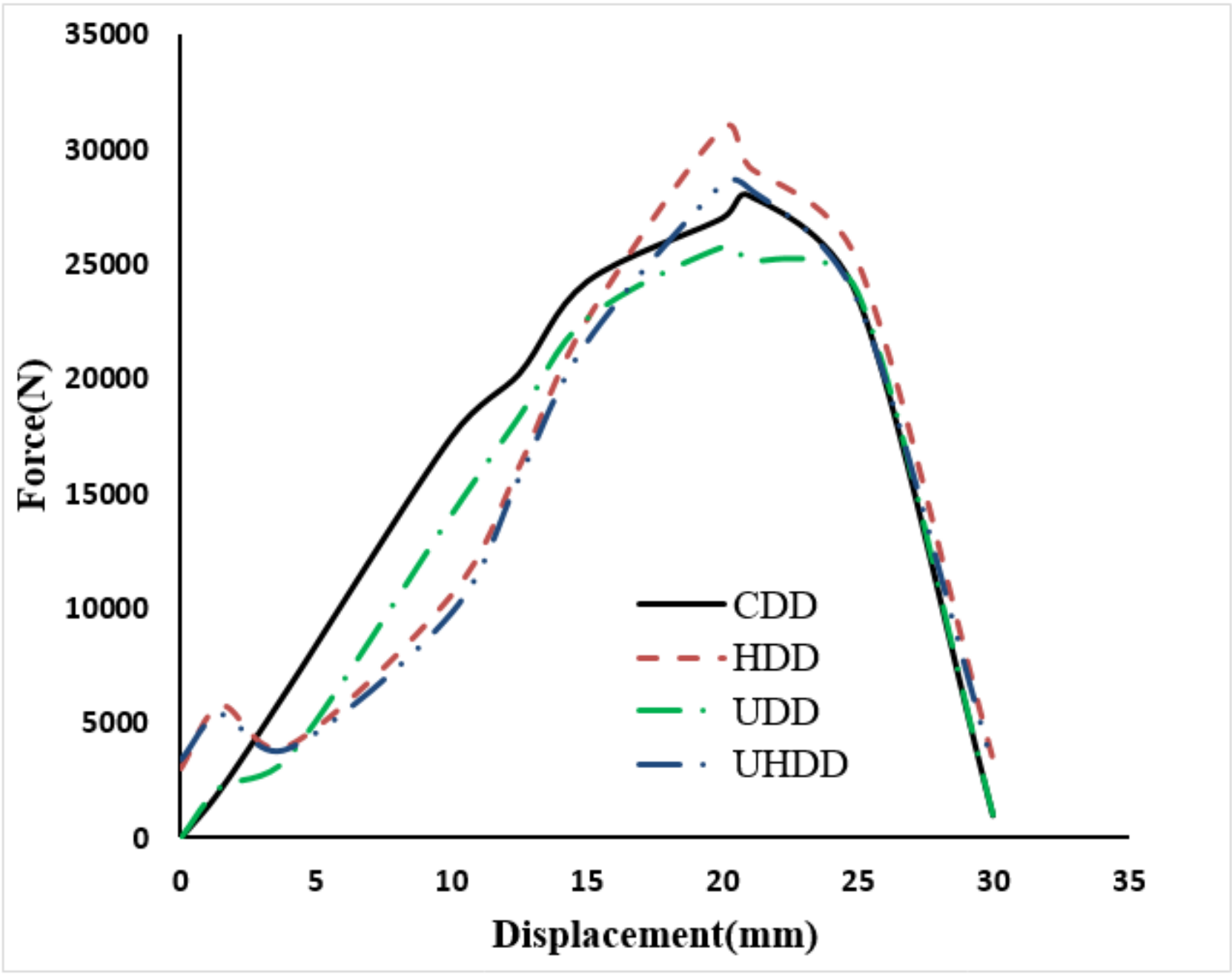

Figure 11

Compare of forming force in four steps of experiments at LDR2 


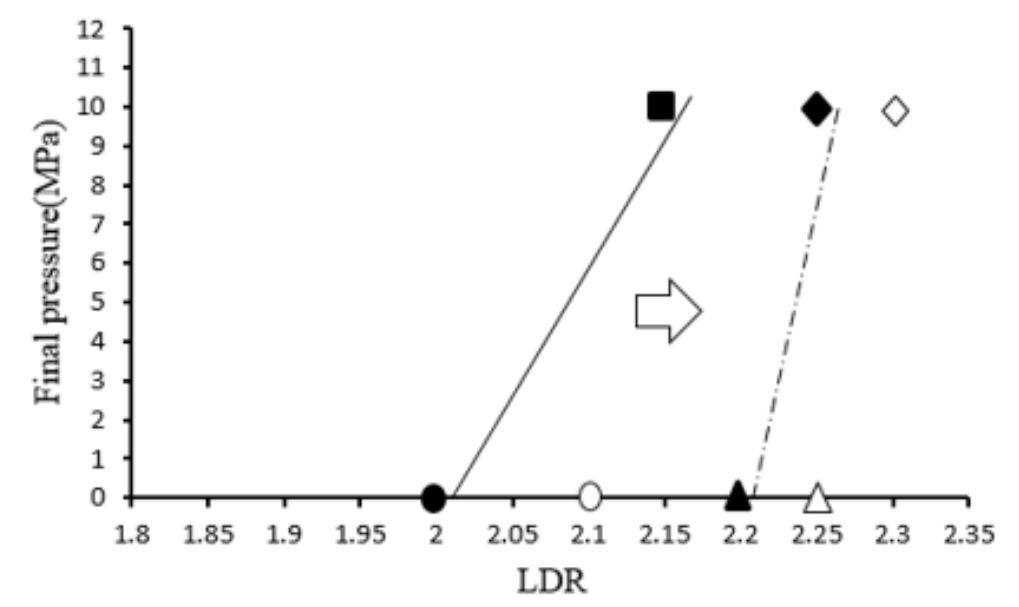

\begin{tabular}{|c|c|c|}
\hline \multirow{2}{*}{ CDD } & $\bullet$ & Successful \\
\cline { 2 - 3 } & 0 & Rupture \\
\hline \multirow{2}{*}{ HDD } & $\mathbf{1}$ & Successful \\
\cline { 2 - 3 } & $\square$ & Rupture \\
\hline \multirow{2}{*}{ UDD } & $\boldsymbol{\Delta}$ & Successful \\
\cline { 2 - 3 } & $\Delta$ & Rupture \\
\hline \multirow{2}{*}{ UHDD } & $\bullet$ & Successful \\
\cline { 2 - 3 } & $\diamond$ & Rupture \\
\hline- & \multicolumn{2}{|c|}{ Conventional Safe Border } \\
\hline$-\cdot-$ & \multicolumn{2}{|c|}{ Safe Border With UV } \\
\hline
\end{tabular}

Figure 12

Working zone in four steps of experiments

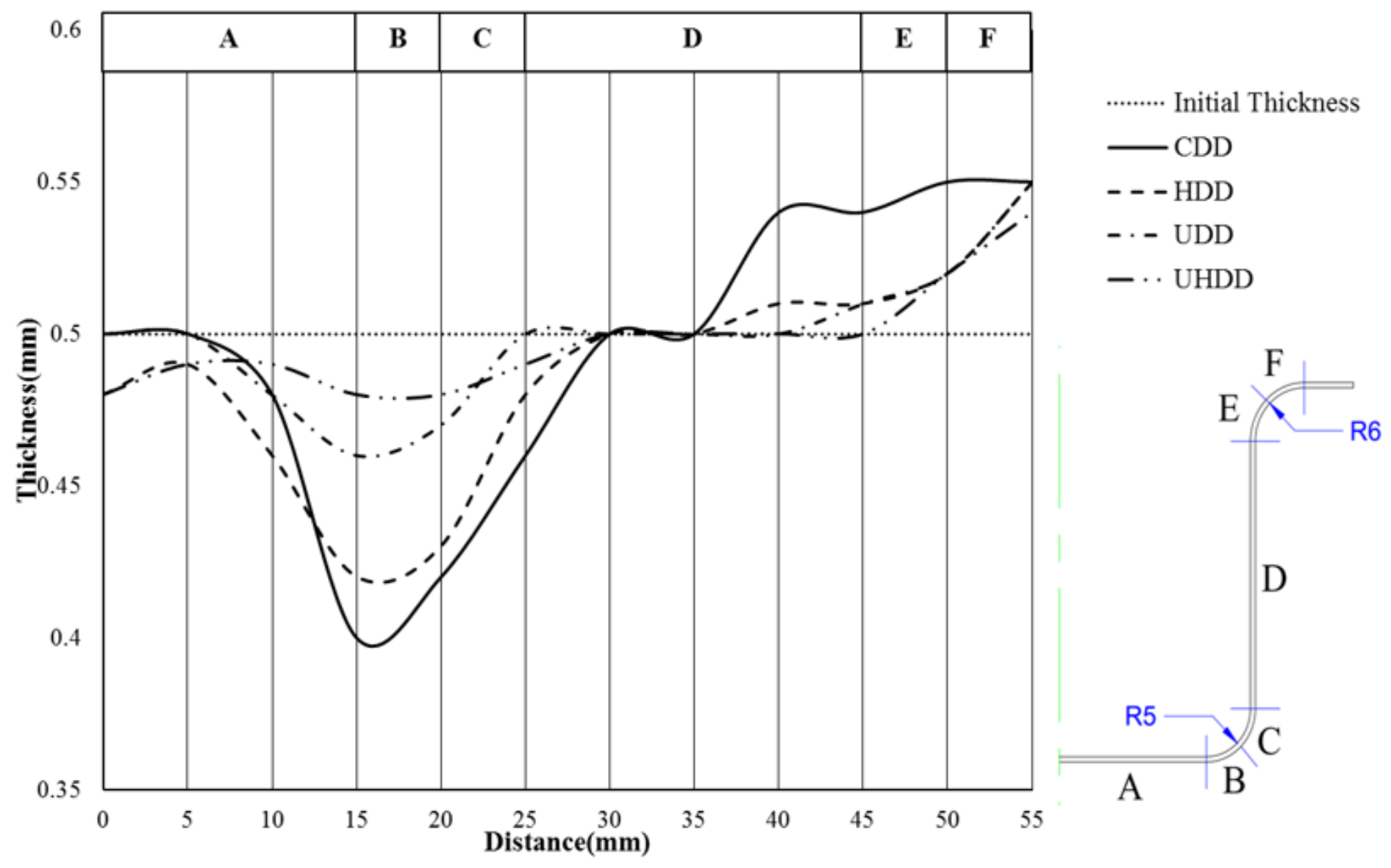

Figure 13

Thickness distribution in four steps of experiment at LDR2 